\title{
Low volume amplification and sequencing of mitochondrial DNA on a chemically structured chip
}

\author{
Sabine Lutz-Bonengel • Timo Sänger • \\ Marielle Heinrich • Ulrike Schön • Ulrike Schmidt
}

Received: 30 May 2006 / Accepted: 29 August 2006 / Published online: 9 November 2006

(C) Springer-Verlag 2006

\begin{abstract}
Low volume (LV) amplification $(1 \mu \mathrm{L})$ of nuclear DNA (nucDNA) on a chemically structured chip is an appropriate and highly sensitive method to simultaneously amplify amelogenin and 15 forensically relevant short tandem repeats (STR). In this study, a combined method using on-chip LV amplification of mitochondrial DNA (mtDNA) and subsequent on-chip LV cycle sequencing was established to obtain a method, which is sensitive and robust enough to allow reliable analysis of DNA amounts representing the single cell level. All the necessary steps of the procedure- except for the purification of the sequencing products - were accomplished within the same final $2-\mu \mathrm{L}$ reaction volume.
\end{abstract}

Keywords Low volume amplification .

On-chip amplification · On-chip cycle sequencing ·

Mitochondrial DNA

\section{Introduction}

In the field of forensic DNA analysis including identification, stain analysis and kinship testing, the investigation of short tandem repeat (STR) markers of nuclear DNA has proven to be a valuable and sensitive method $[13,15,18]$.

S. Lutz-Bonengel $(\varangle) \cdot$ T. Sänger $\cdot$ M. Heinrich $\cdot$ U. Schmidt Institute of Legal Medicine, Albert Ludwig University Freiburg, Albertstrasse 9,

79104 Freiburg, Germany

e-mail: sabine.lutz-bonengel@uniklinik-freiburg.de

U. Schön

Alopex $\mathrm{GmbH}$,

Fritz-Hornschuch-Strasse 9,

95326 Kulmbach, Germany
The sensitivity of the PCR reaction can be improved by using short amplicon primers [3, 8]. This strategy is based on the experience that in degraded DNA samples a successful amplification of short amplicons is more likely.

In casework, problems frequently occur, which cannot be resolved using conventional STR typing. Therefore, alternative techniques need to be applied. For instance, deficiency cases can be solved by sequence analysis of the mitochondrial control region or by analysis of Y-chromosome and X-chromosome specific STRs [4, 7, 19, 26, 27]. If only highly degraded DNA is available for analysis, typing of single nucleotide polymorphisms (SNPs) can be the method of choice [24]. Applying this method on a microarray system combines the high sensitivity of SNP typing with the high efficiency of modern analysis strategies [10].

The high copy number of mitochondrial genomes per cell [5, 21, 23] allows successful PCR amplification even in cases where only very low amounts of nuclear DNA are available as known from low copy number (LCN) samples, such as hair shafts or skin flakes $[20,26]$. The detection and analysis of mitochondrial SNPs allows the assignment of individuals to specific mitochondrial haplogroups $[6,12]$.

An additional enhancement of PCR sensitivity can be achieved by the reduction of the reaction volume $[11,16$, 17]. Investigations of low volume multiplex reactions on a chemically structured chip showed successful amplification from as little as $32 \mathrm{pg}$ of cell line DNA revealing a full STR profile [22]. However, some problems occurred when working with low volume on-chip PCR: dropout of loci and single alleles were observed, which can be interpreted as stochastic effects due to pipetting of very small volumes [14].

Working with this chip provides several advantages, such as lowering the costs of PCR reagents by reducing the 
reaction volume, easy handling, uncomplicated integration in laboratory routine processes and the possibility to apply the template material under optical control. These advantages have prompted us to further validate additional techniques on the chip, such as the direct sequencing method of the mitochondrial genome.

The abovementioned problems occurring in the context of LV/LCN amplification of STRs are unlikely to occur in the context of mtDNA typing because low volumes of sample are expected to carry more target copies of mtDNA than the nuclear genome. Furthermore, sequences are investigated rather than length-variants. On-chip PCR followed by sequencing analysis could be sensitive enough to provide a reliable technique for single cell analysis. The challenge is to create a method that permits PCR to be performed with subsequent sequencing analysis in the same reaction volume.

This article presents a strategy for amplification and direct sequencing of mitochondrial DNA on a chemically structured chip. The quality of this method will be compared to the analogous in-tube LV reaction and to the standardised amplification and sequencing in-tube reaction in a $25-\mu \mathrm{L}$ volume.

\section{Materials and methods}

Samples, DNA extraction and quantification

Total DNA from a peripheral blood sample was extracted as follows: the EDTA-treated blood sample was first frozen and thawed, washed with $1 \mathrm{ml}$ of $1 \mathrm{X}$ SSC buffer (15 mM sodium citrate, $150 \mathrm{mM}$ sodium chloride) and nuclei and organelles were pelleted by centrifugation $(5 \mathrm{~min}$ at $8000 \times \mathrm{g}$ ). After discarding the supernatant, the pellet was washed twice with $1 \mathrm{X} \mathrm{SSC}$ buffer and centrifuged again $(5 \mathrm{~min}$ at $8000 \times \mathrm{g})$. The pelleted nuclei and organelles were resuspended in $700 \mu \mathrm{L}$ bidistilled water, then $50 \mu \mathrm{L}$ $3 \mathrm{M}$ sodium acetate, $\mathrm{pH} 7.0,50 \mu \mathrm{L} 10 \%$ SDS and $20 \mu \mathrm{L}$ Proteinase K $(20 \mathrm{mg} / \mathrm{ml})$ were added and the sample was incubated overnight at $56^{\circ} \mathrm{C}$. DNA purification was performed by three extraction steps with water saturated phenol, phenol:chloroform:isoamylalcohol (25:24:1) and finally chloroform:isoamylalcohol (24:1). Total DNA was precipitated with ethanol and the pellet was washed with $70 \%$ ethanol. Finally, the dried pellet was resuspended in $200 \mu \mathrm{L}$ bidistilled water.

The content of nuclear DNA within the DNA extract was quantified using the Quantifiler ${ }^{\mathrm{TM}}$ Human DNA Quantification Kit (Applied Biosystems, Foster City, CA). Then, DNA was diluted with sterile water to obtain 12 samples with DNA contents of $1,000,500,250,100,50,40,30,20$, $10,5,2.5$ and $1 \mathrm{pg} / \mu \mathrm{L}$ of nuclear DNA, respectively. To confirm the nuclear DNA content, all diluted samples were quantified again. To determine the corresponding mtDNA content, 800-900 mtDNA genome equivalents per cell [2, $9,28]$, or rather $128 \pm 11$ mtDNA genome equivalents per pg chromosomal DNA were calculated (personal communication: H. Niederstätter, GMI, Innsbruck, Austria).

Chips

Chips were supplied by Alopex (Kulmbach, Germany). These are chemically structured glass slides, originally developed for single cell analysis and quantification of single genome equivalents. Biochemical reactions proceed on 60 lithographically defined hydrophilic anchor spots, each framed by a hydrophobic ring. Each of the reaction compartments can hold up to $2 \mu \mathrm{L}$ of aqueous solution.

Low volume DNA amplification and subsequent sequencing on chemically structured chips

A total volume of $1 \mu \mathrm{L}$ PCR reaction mix, containing $0.1 \mu \mathrm{L}$ AmpliTaq Gold $(5 \mathrm{U} / \mu \mathrm{L}), 0.1 \mu \mathrm{L}$ 10X GeneAmp PCR buffer I (both: Applied Biosystems), 0.1 $\mu \mathrm{L}$ dNTP mix (2.5 mM each), $0.2 \mu \mathrm{L}$ PCR primer set L29/H381

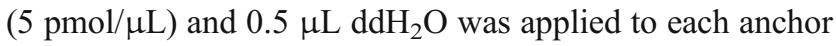
spot and dried for $20 \mathrm{~min}$ to allow slight evaporation of fluid and to allow for the application of the template. Then, $1 \mu \mathrm{L}$ of (diluted) DNA template (total DNA) was added and each reaction compartment was covered with $5 \mu \mathrm{L}$ of covering solution (Alopex). Cycling was performed using an Eppendorf Mastercycler with in situ adapter (Eppendorf, Hamburg, Germany). Thermal cycling conditions for primer set L29/H381 (cf. Table 1) were an initial heating step of $95^{\circ} \mathrm{C}$ for $10 \mathrm{~min}, 32$ cycles of $94^{\circ} \mathrm{C}$ for $20 \mathrm{~s}, 56^{\circ} \mathrm{C}$ for $10 \mathrm{~s}, 72^{\circ} \mathrm{C}$ for $30 \mathrm{~s}$ and a final extension at $72^{\circ} \mathrm{C}$ for $10 \mathrm{~min}$. Negative controls were performed on different positions on the chip using the same reagent solutions without DNA.

The 60 anchor spots of each chip were supplied with 12 no-template controls and with quadruplicates of the 12 differently concentrated DNA samples. After amplification,

Table 1 Sequences of primers used for mitochondrial DNA amplification and sequencing

\begin{tabular}{ll}
\hline $\begin{array}{l}\text { PCR and sequencing } \\
\text { primers }\end{array}$ & Nucleotide sequence \\
\hline L29 & 5'-CTCACGGGAGCTCTCCATGC-3' \\
H381 & 5'-GCTGGTGTTAGGGTTCTTTG-3' \\
\hline
\end{tabular}

The primers are named according to the position of their $3^{\prime}$-ends within the reference sequence [1]. " $\mathrm{"} \mathrm{and} \mathrm{"} H$ " indicate the light and heavy strands of the mitochondrial DNA molecule 
6 out of 12 no-template controls and 2 samples from each of the 12 quadruplicate reactions were electrophoresed on a $2 \%$ agarose gel (TBE). The remaining 30 reactions (another 2 samples of the 12 quadruplicate reactions plus 6 no-template controls) were retained on the chip and treated as follows: After cycling, $0.4 \mu \mathrm{L}$ ExoSap-IT (USB, Cleveland, OH) was added to the hydrophilic phase and incubated $\left(37^{\circ} \mathrm{C}\right.$ for $15 \mathrm{~min}$ ) to degrade residual primers and dNTPs by enzymatic treatment. After inactivation of the enzymes at $80^{\circ} \mathrm{C}$ for $15 \mathrm{~min}, 0.6 \mu \mathrm{L}$ BigDye-Primer-Mix was added, containing $0.5 \mu \mathrm{L}$ BigDye Terminator v1.1 (BDTv1.1) Cycle Sequencing Kit (Applied Biosystems) and $0.1 \mu \mathrm{L}$ sequencing primer (10 pmol/ $\mu \mathrm{L})$ (L29 or H381; cf. Table 1). Cycle sequencing was performed on an Eppendorf Mastercycler with in situ adapter (Eppendorf). Thermal cycling conditions were an initial heating step of $96^{\circ} \mathrm{C}$ for $1 \mathrm{~min}, 25$ cycles of $96^{\circ} \mathrm{C}$ for $10 \mathrm{~s}, 50^{\circ} \mathrm{C}$ for $10 \mathrm{~s}$ and $60^{\circ} \mathrm{C}$ for $4 \mathrm{~min}$. After cycling, aqueous and oily components were removed from each spot, brought to a final volume of $20 \mu \mathrm{L}$ with bidistilled water and purified using AutoSeq G-50 columns (GE Healthcare, München). Electrophoretic separation of each sample was carried out on an ABI Prism 3100 Genetic Analyser.

To exclude contaminations, all sequences were aligned and compared to the Cambridge reference sequence (CRS) [1] and to the base sequence of the respective donor and laboratory staff involved using SeqScape (version 2.1) (Applied Biosystems).

Low volume DNA amplification and subsequent sequencing in a PCR tube

The procedure of in-tube LV amplification was performed as follows: $1 \mu \mathrm{L}$ PCR reaction mixes were pipetted into $0.2 \mathrm{ml}$ thin-walled PCR tubes and immediately covered with $5 \mu \mathrm{L}$ of covering solution (Alopex). DNA-containing samples were analysed in quadruplicate together with 12 no-template controls. Amplification, purification, sequencing and detection of the products were performed as described for chips.

Conventional DNA amplification in PCR reaction tubes and subsequent sequencing

Amplification was performed in a $0.2 \mathrm{ml} \mathrm{PCR} \mathrm{tube} \mathrm{in} \mathrm{a} \mathrm{total}$ volume of $25 \mu \mathrm{L}$. Each reaction contained $1 \mu \mathrm{L}$ template dilution, $0.25 \mu \mathrm{L}$ AmpliTaq Gold (5 U/ $\mu \mathrm{L}), 2.5 \mu \mathrm{L} 10 \mathrm{X}$ GeneAmp buffer I (Applied Biosystems), $0.5 \mu \mathrm{L}$ BSA $(5 \mathrm{mg} / \mathrm{ml})$, $2 \mu \mathrm{L}$ dNTP mix (2.5 mM each), $2 \mu \mathrm{L}$ primer set L29/H381 (5 pmol $/ \mu \mathrm{L}$ ) and $16.75 \mu \mathrm{L} \mathrm{ddH}_{2} \mathrm{O}$. Thermal cycling conditions were as described for chips. The PCR products were separated from the residual primers, dNTPs and buffer using the QIAquick PCR purification kit (Qiagen, Hilden, Germany) according to the manufacturer's recommenda- tions. The 12 DNA-containing samples were analysed in duplicate together with 6 no-template controls. After amplification, $5 \mu \mathrm{L}$ of each of the 30 in-tube reactions were separated by electrophoresis in a $2 \%$ agarose gel (TBE). In addition, $2 \mu \mathrm{L}$ of each amplification product was used for the cycle sequencing reactions, which were performed in a total volume of $10 \mu \mathrm{L}$. Each reaction contained $2 \mu \mathrm{L}$ template, $2 \mu \mathrm{L}$ BigDye Terminator v1.1 Cycle Sequencing Kit (Applied Biosystems), $2 \mu \mathrm{L} 5 \mathrm{X}$ sequencing buffer for BDTv1.1 (article number: 4336697), $1 \mu \mathrm{L}$ sequencing primer (L29 or $\mathrm{H} 381)(2 \mathrm{pmol} / \mu \mathrm{L})$ and $3 \mu \mathrm{L} \mathrm{ddH}_{2} \mathrm{O}$. Thermal cycling conditions were the same as described for chips. After cycle sequencing, the reactions were brought to a final volume of $20 \mu \mathrm{L}$ with bidistilled water and purified using AutoSeq G-50 columns (GE Healthcare). Analysis was performed by capillary electrophoresis on an ABI Prism 3100 Genetic Analyser. To exclude contaminations, all sequences were aligned and compared to the CRS and to the base sequence of the respective donor and laboratory staff involved using SeqScape (version 2.1) (Applied Biosystems).

\section{Results and discussion}

Illustrative examples for mtDNA amplification and sequencing results obtained from the different methods $-1 \mu \mathrm{L}$ onchip, $1 \mu \mathrm{L}$ in-tube, and $25 \mu \mathrm{L}$ in-tube - are given in Figs. 1 and 2. Unless stated otherwise, the quantity values mentioned in the text refer to nucDNA.

PCR products could be generated from template concentrations down to $1 \mathrm{pg}$ using $1-\mu \mathrm{L}$ on-chip amplification (cf. Fig. 1). One amplification from $2.5 \mathrm{pg}$ failed. Higher template concentrations ( $40 \mathrm{pg}-1 \mathrm{ng}$ ) yielded unspecific products on the agarose gel. The corresponding $1-\mu \mathrm{L}$ intube amplification generated detectable PCR product from template concentrations down to $5 \mathrm{pg}$ (cf. Fig. 1). Unspecific products were not observed. Using conventional 25$\mu \mathrm{L}$ in-tube amplification, detectable products could also be amplified from template concentrations between $2.5 \mathrm{pg}$ and $1 \mathrm{ng}$. All negative controls revealed the expected results.

The reactions chosen for Fig. 1 exemplarily reflect the outcome of the respective procedure as we observed it throughout the study: As visualized by ethidium bromide staining, the in-tube LV amplification shows the weakest bands and thus, the lowest sensitivity. In contrast, the same reaction volume on the chip shows the strongest bands in the agarose gel. In addition, the on-chip LV amplification appears to be the reaction of highest sensitivity due to successful amplification of $1 \mathrm{pg}$ of template DNA. Because the reaction components of the $1-\mu \mathrm{L}$ in-tube and on-chip reactions are identical, the conspicuously higher PCR efficiency of the on-chip reaction may be caused by the 
Fig. 1 Amplification products of the LV amplifications performed on-slide and in-tube and the conventional amplification in $25-\mu \mathrm{L}$ reactions. The products were electrophoresed on a $2 \%$ agarose gel with ethidium bromide staining. Template amounts (nucDNA) of each reaction are given on top of each lane. $1 \mathrm{pg}$ nucDNA corresponds to $128 \pm 11 \mathrm{mtDNA}$ genomes. From each diluted DNA sample, two reactions were transferred to the agarose gel, visualized by the frame surrounding the first two samples. $\mathrm{L}=100 \mathrm{bp}$ ladder, $\mathrm{nc}=$ negative control

\section{On-chip PCR, $1 \mu \mathrm{L}$}
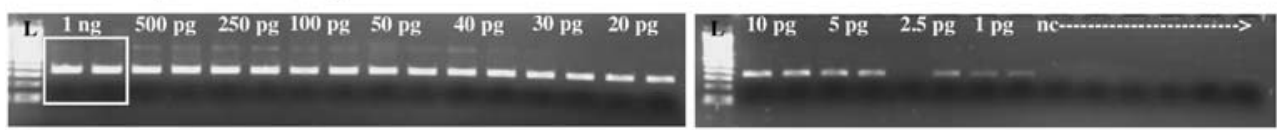

In-tube PCR, $1 \mu \mathrm{L}$
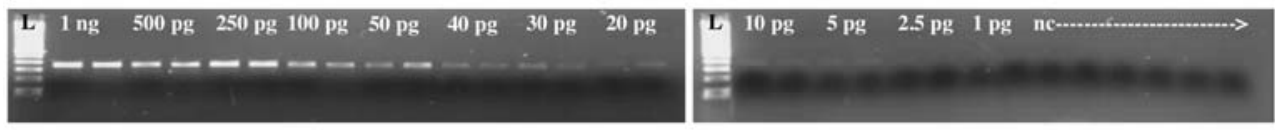

In-tube PCR, $25 \mu \mathrm{L}$
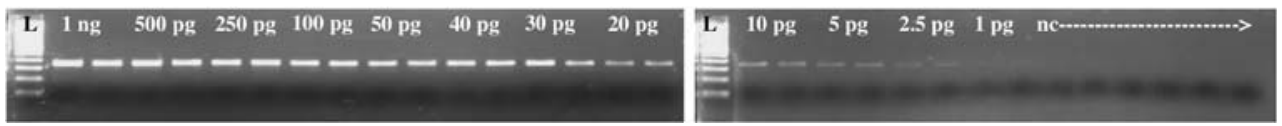

different reaction platforms, e.g. changes in thermal transfer. Still, in a few cases the $1-\mu \mathrm{L}$ on-chip amplification of "unproblematic" amounts of template yielded no detectable product; a satisfactory explanation for this phenomenon could not be found.

Comparing the $1-\mu \mathrm{L}$ on-chip and $25-\mu \mathrm{L}$ in-tube reactions, the bands of the conventional $25-\mu \mathrm{L}$ reactions appeared to be generally weaker. In addition, no bands were visible whenever template amounts of less than $2.5 \mathrm{pg}$ nucDNA were tested. This finding can be explained by different efficiencies of the methods regarding the amount of amplified product per $\mu \mathrm{L}$. In this respect, it also has to be considered that the whole reaction volume of the $1-\mu \mathrm{L}$ onchip reaction but only one-fifth of the $25-\mu \mathrm{L}$ reaction was transferred to the agarose gel. Although the difference in detection limits of the two methods may seem negligibly small ( $1 \mathrm{pg}$ vs $5 \mathrm{pg}$ ), it has to be kept in mind that the quantities refer to nucDNA. Regarding the number of mtDNA genomes, this difference corresponds to approximately 500 template copies (128 vs 640 mtDNA genomes). Also, the electrophoretical separation in agarose gels is a rather imprecise method for quantification of PCR products. Altogether, this test does not-and was not intended to-

Fig. 2 Sections of the electropherograms obtained from the $1 \mu \mathrm{L}$ on-chip and in-tube cycle sequencing reactions and from the conventional cycle sequencing reactions in $25 \mu \mathrm{L}$ volumes. The respective amounts of nucDNA and the corresponding number of mitochondrial genomes are indicated. $\mathrm{mtGE}=$ mitochondrial genome equivalents; $\mathrm{nr}=$ no results obtained

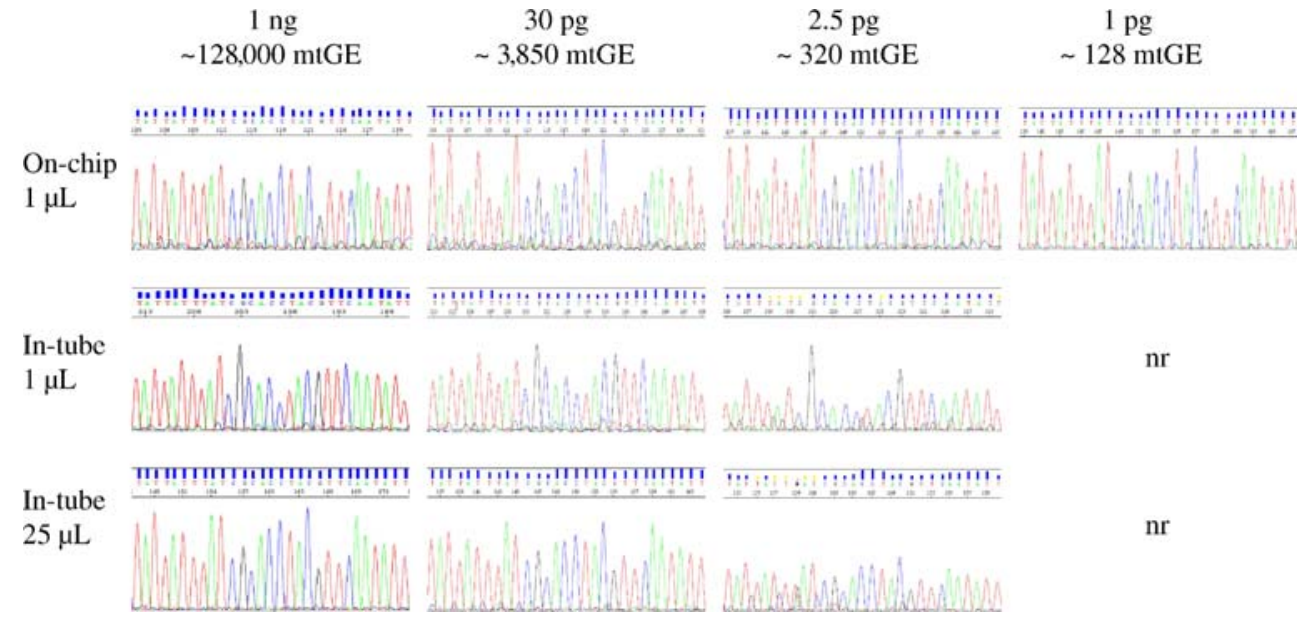

definitely assess the two procedures' sensitivities, which seem to be comparable at least, but it sure gives a general survey.

The sequencing results give further information about the success of the three strategies compared. Overall, cycle sequencing of PCR products from on-chip amplification of $1 \mathrm{pg}$ to $1 \mathrm{ng}$ template was successful. Again, in a few cases sequencing reaction of normally "unproblematic" amounts of template failed. In these cases, it was not possible to account the failure to the relevant reaction because the very small reaction volume of $1 \mu \mathrm{L}$ was either completely used for detection on the agarose gel—revealing success or failure of the amplification - or was subjected to cycle sequencing and capillary electrophoresis. In general, about $300 \mathrm{bp}$ of good quality sequence electropherograms were obtained. Unspecific products as observed at agarose gel analysis did not interfere with the quality of the sequencing results.

In-tube amplifications yielded sequencing data down to $2.5 \mathrm{pg}$ of diluted nucDNA, which is equivalent to about 320 mtDNA genomes.

Representative examples of sequencing electropherograms typically obtained from on-chip LV, in-tube LV and conventional $25-\mu \mathrm{L}$ reactions are given in Fig. 2. The 
respective amounts of nucDNA as quantified and the corresponding numbers of mtDNA genomes are indicated. Again, the examples reflect the strengths and limitations of the respective procedure: Although the detection limits of on-chip PCR $(1 \mu \mathrm{L})$ and in-tube PCR $(25 \mu \mathrm{L})$ seem to be comparable, the quality of sequencing data derived from the respective PCR products clearly vary. The conventional $25-\mu \mathrm{L}$ reaction is better suited than the other strategies whenever higher template amounts are analyzed (500 pg$1 \mathrm{ng})$. The on-chip reaction shows the best sequencing results for low concentrations of template (less than $20 \mathrm{pg}$ ). However, enlargement of the anchor spots and therefore the possibility of using higher amounts of Big-Dye-mix may lead to further improvement of the sequencing results, particularly to a longer range of good quality sequence.

Regarding the sequence electropherograms obtained from on-chip reactions $(1 \mu \mathrm{L})$, background fluorescence signals obviously decreased with reduced amount of template. Whenever low template amounts were analyzed (corresponding to $2.5 \mathrm{pg}$ of nucDNA and less), this method outperformed the in-tube reactions. Sequencing data from mtDNA corresponding to $1 \mathrm{pg}$ of nucDNA was only obtained by LV on-chip amplification and sequencing, and it often was of good quality (cf. Fig. 2). In comparison, the sequence electropherograms derived by $1-\mu \mathrm{L}$ in-tube amplification and sequencing tended to show unbalanced signals and a rather high fluorescence background. Sequencing data from low template amounts were ambiguous and often did not meet basic standards of quality. Still, the analysis of higher template amounts using conventional in-tube reactions $(25 \mu \mathrm{L})$ generated the most excellent sequencing results with intense signals and with the lowest fluorescence background. Whenever mtDNA corresponding to $20 \mathrm{pg}$ of nucDNA or less were analyzed, the quality of the sequencing data markedly decreased. Also, in-tube reactions $(1 \mu \mathrm{L}$ and $25 \mu \mathrm{L}$ ) failed when analyzing very low amounts of mtDNA (1 pg nucDNA).

Similar results were observed when the analogous experiments were performed using primer set $\mathrm{L} 15 / \mathrm{H} 484$ (data not shown).

Altogether, we have designed an accurate and efficient method for the amplification and sequencing of mitochondrial genomes on a LV reaction platform. As the results show, amplification of mitochondrial DNA with subsequent sequencing in the same reaction volume is practicable on a chemically structured chip. The quality of the obtained results is well comparable to those obtained from a $25-\mu \mathrm{L}$ reaction.

Problems that appeared in on-chip STR analysis, e.g. elevated stutter peaks or imbalance of heterozygous loci did not occur in the sequencing of mitochondrial DNA because the underlying PCR reaction is a "one-allelic" reaction. In addition, incomplete fragments remain indiscernible when using the dideoxy sequencing method with labelled ddNTPs. The single peak heights of the electropherograms appeared well-balanced.

Because the anchor spots of the chip resemble an "open" reaction system one would expect a higher risk for cross-contamination. This presumption could not be demonstrated in our study. Quite the contrary, decontaminating of the chip surface, e.g. by UV exposure, is easy to perform. Covering the reaction mix with covering solution seems to prevent cross-contamination very effectively. In a total of 250 negative controls performed in the context of this study, only 1 single contamination event was observed.

Chip handling is convenient due to the segmentation of the surface in hydrophobic and hydrophilic compartments. With the help of the chemically modified surface of the slide, solutions are safely kept in position and spots are clearly separated from each other. For the application of samples to the anchor spots, the use of a pipette for very small volumes $(0.1-2.5 \mu \mathrm{L})$ is advisable. It is important that the reaction remains free of gas bubbles because heatinduced ascension of gas bubbles during PCR or sequencing reactions may destroy the hemispherical shape of the reaction mix.

One serious drawback of the low volume approach of PCR with subsequent sequencing is that replications of sequencing reactions from the same PCR product are not possible. Similarly, there is no possibility of sequencing forward and reverse strands from one single PCR product. Therefore, the method presented here is suitable for specific problems that cannot be solved otherwise.

On the other hand, a great benefit of the chip-based analyses is the possibility of applying single cells under optical control. The sensitivity of the technique allows for the successful amplification of amounts of mitochondrial DNA equivalent to $1 \mathrm{pg}$ of genomic template DNA. Thus, this method establishes a promising base for the investigation of topics concerning the composition of mtDNA molecules on a single cell level, e.g. in consideration of mitochondrial heteroplasmy.

\section{References}

1. Anderson S, Bankier AT, Barrell BG, de Bruijn MHL, Coulson AR, Drouin J, Eperon IC, Nierlich DP, Roe BA, Sanger F, Schreier PH, Smith AJH, Staden R, Young IG (1981) Sequence and organization of the human mitochondrial genome. Nature 290:457-464

2. Andréasson H, Gyllensten U, Allen M (2002) Real-time DNA quantification of nuclear and mitochondrial DNA in forensic analysis. Biotechniques 33:402-411

3. Asamura H, Sakai H, Kobayashi K, Ota M, Fukushima H (2006) MiniX-STR multiplex system population study in Japan and application to degraded DNA analysis. Int J Legal Med 120:174-181 
4. Berger B, Lindinger A, Niederstätter $\mathrm{H}$, Grubwieser P, Parson W (2005) Y-STR typing of an Austrian population sample using a 17-loci multiplex PCR assay. Int J Legal Med 119:241-246

5. Bogenhagen D, Clayton DA (1974) The number of mitochondrial deoxyribonucleic acid molecules in mouse $\mathrm{L}$ and human $\mathrm{HeLa}$ cells. J Biol Chem 249:7991-7995

6. Brandstätter A, Parsons TJ, Parson W (2003) Rapid screening of mtDNA coding region SNPs for the identification of west European Caucasian haplogroups. Int J Legal Med 117:291-298

7. Budowle B, Allard MW, Wilson MR, Chakraborty R (2003) Forensics and mitochondrial DNA: applications, debates, and foundations. Annu Rev Genomics Hum Genet 4:119-141

8. Butler JM, Shen Y, McCord BR (2003) The development of reduced size STR amplicons as tools for analysis of degraded DNA. J Forensic Sci 48:1054-1064

9. Chong MD, Calloway CD, Klein SB, Orrego C, Buoncristiani MR (2005) Optimization of a duplex amplification and sequencing strategy for the HVI/HVII regions of human mitochondrial DNA for forensic casework. Forensic Sci Int 154:137-148

10. Divne AM, Allen MA (2005) DNA microarray system for forensic SNP analysis. Forensic Sci Int 154:111-121

11. Gaines ML, Wojtkiewicz PW, Valentine JA, Brown CL (2002) Reduced volume PCR amplification reactions using the AmpFISTR Profiler Plus kit. J Forensic Sci 47:1224-1237

12. Grignani P, Peloso G, Achilli A et al (2006) Subtyping mtDNA haplogroup $\mathrm{H}$ by $\mathrm{SNaPshot} \mathrm{minisequencing} \mathrm{and} \mathrm{its} \mathrm{application} \mathrm{in}$ forensic individual identification. Int J Legal Med 120:151-156

13. Grubwieser P, Zimmermann B, Niederstätter H, Pavlic M, Steinlechner M, Parson W (2006) Evaluation of an extended set of 15 candidate STR loci for paternity and kinship analysis in an Austrian population sample. Int J Legal Med, DOI 10.1007/ s00414-006-0079-9

14. Kloosterman AD, Kersbergen P (2003) Efficacy and limits of genotyping low copy number (LCN) DNA samples by multiplex PCR of STR loci. J Soc Biol 197:351-359

15. Krenke BE, Tereba A, Anderson SJ et al (2002) Validation of a 16-locus fluorescent multiplex system. J Forensic Sci 47:773-785

16. Kricka LJ, Wilding P (2003) Microchip PCR. Anal Bioanal Chem 377:820-825
17. Leclair B, Sgueglia JB, Wojtowicz PC, Juston AC, Fregeau CJ, Fourney RM (2003) STR DNA typing: increased sensitivity and efficient sample consumption using reduced PCR reaction volumes. J Forensic Sci 48:1001-1013

18. Lygo JE, Johnson PE, Holdaway DJ et al (1994) The validation of short tandem repeat (STR) loci for use in forensic casework. Int J Legal Med 107:77-89

19. Parson W, Niederstätter H, Brandstätter A, Berger B (2003) Improved specificity of Y-STR typing in DNA mixture samples. Int J Legal Med 117:109-114

20. Pfeiffer H, Hühne J, Ortmann C, Waterkamp K, Brinkmann B (1999) Mitochondrial DNA typing from human axillary, pubic and head hair shafts - success rates and sequence comparisons. Int J Legal Med 112:287-290

21. Robin ED, Wong R (1988) Mitochondrial DNA molecules and virtual number of mitochondria per cell in mammalian cells. J Cell Physiol 13:507-513

22. Schmidt U, Lutz-Bonengel S, Weisser H-J et al (2006) Low volume amplification on chemically structured chips using the PowerPlex16 DNA amplification kit. Int J Legal Med 120:42-48

23. Shadel GS, Clayton DA (1997) Mitochondrial DNA maintenance in vertebrates. Annu Rev Biochem 66:409-435

24. Sobrino B, Carracedo A (2005) SNP typing in forensic genetics. Methods Mol Biol 297:107-126

25. Szibor R, Michael M, Plate I, Krause D (2000) Efficiency of forensic mtDNA analysis. Case examples demonstrating the identification of traces. Forensic Sci Int 113:71-78

26. Szibor R, Krawczak M, Hering S, Edelmann J, Kuhlisch E, Krause D (2003) Use of X-linked markers for forensic purposes. Int J Legal Med 117:67-74

27. Szibor R, Hering S, Kuhlisch E, Plate I, Demberger S, Krawczak M, Edelmann J (2005) Haplotyping of STR cluster DXS6801DXS6809-DXS6789 on Xq21 provides a powerful tool for kinship testing. Int J Legal Med 119:363-369

28. Timken MD, Swango KL, Orrego C, Buoncristiani MR (2005) A duplex real-time qPCR assay for the quantification of human nuclear and mitochondrial DNA in forensic samples: implications for quantifying DNA in degraded samples. J Forensic Sci 50:1044-1060 